\title{
Lagoas de transbordo aplicadas para o melhoramento de efluentes anaeróbios destinados a lagoas de polimento
}

\section{Transfer ponds applied to improve anaerobic effluents before post treatment in polishing ponds}

\author{
- Data de entrada: \\ 28/01/2020 \\ - Data de aprovação: \\ 28/09/2020
}

Francisca Kamila Amancio Frutuoso' ${ }^{1}$ Silvânia Lucas dos Santos ${ }^{2}$ | Adrianus van Haandel ${ }^{3}$ DOI: https://doi.org/10.36659/dae.2021.024

ORCID ID

Frutuoso FKA (D) https://orcid.org/0000-0003-3519-6704
Santos SL (iD https://orcid.org/0000-0002-6905-3966 Haandel A (ID) https://orcid.org/0000-0002-9937-6715

\section{Resumo}

Para operar lagoas de polimento em regime de bateladas sequenciais (LPBS) pode ser conveniente ter uma lagoa de transbordo (LT) com a finalidade de receber continuamente o efluente do UASB e alimentar com bateladas as LPBS. Neste trabalho, operaram-se três LTs, em escala piloto, com diferentes profundidades e tempos de detenção hidráulica (TDH) de 1,5 a 3 dias. Os resultados apresentaram ótimas eficiências na remoção de sólidos suspensos (SS) e ovos de helmintos $(\mathrm{OH})$. Não houve diferença significativa $(p>0,05)$ para os SS em relação ao TDH, enquanto para os $\mathrm{OH}$ as eficiências foram da ordem de $90 \%$ em todas as lagoas e TDH. Verificou-se uma variação de $51 \%$ a $14 \%$ de eficiência na remoção de DQQ , decrescendo do maior ao menor TDH. Ademais, notaram-se outros processos, tais como: início da proliferação de algas, dessorção de $\mathrm{CO}_{2} \mathrm{e}$ diminuição da concentração de sulfeto. Conclui-se que lagoas de transbordo podem ser uma alternativa no melhoramento do tratamento de efluentes destinados às LPBS.

Palavras-chave: Tratamento de esgoto. Lagoa de estabilização. UASB. Lagoa de polimento em bateladas sequenciais. Lagoa de transbordo.

\section{Abstract}

To operate sequential batch polishing ponds (SBPP), it may be convenient to operate a transfer pond (TP) that receives effluent from the continuous flow UASB reactor and feeds batches to the polishing ponds. In this work, three TPs were operated, on a pilot scale, with different depths and hydraulic retention time (HRT) of 1.5 to 3 days. The results showed excellent efficiencies in the removal of suspended solids (SS) and helminth eggs. There was no significant difference ( $p>0.05$ ) in SS in relation to HRT, while for helminth eggs the efficiencies were in the order of $90 \%$ in all ponds and HRT. There was a variation of $51 \%$ to $14 \%$ in efficiency when removing COD, decreasing from the highest to the lowest HRT. In addition, other processes were noted, such as: beginning of algae proliferation, $\mathrm{CO}_{2}$ desorption and decreased sulfide concentration. It is concluded that overflow ponds can be an alternative in improving the treatment of effluents destined to SBPP.

Keywords: Sewage treatment. Stabilization ponds. UASB reactor. Sequential batch polishing pond. Transfer ponds.

\footnotetext{
${ }^{1}$ Universidade Federal do Ceará - UFC - Fortaleza - Ceará - Brasil.

2 Universidade Federal do Rio Grande do Norte - UFRN - Natal - Rio Grande do Norte - Brasil.

${ }^{3}$ Universidade Federal de Campina Grande - Campina Grande - Paraíba - Brasil.

* Autor correspondente: adrianusvhagmail.com.
} 


\section{INTRODUÇÃO}

As lagoas de estabilização convencionais são sistemas de tratamento amplamente empregados em todo o mundo (KEHL et al., 2009, OLUKANNI e DUCOSTE, 2011; VERBYLA et al., 2013) em decorrência de sua fácil operação, manutenção e bom desempenho (LI et al., 2018; BRYANT, 1986). Apesar de suas vantagens, sua aplicação também está associada a diversas e importantes desvantagens, como a necessidade de uma grande área para sua implantação (MARA e PEARSON, 1987); elevado acúmulo de lodo (CAVALCANTI, 2002); perda de água por evaporação, que provoca a elevação da salinidade do efluente final; geração de odores no entorno do sistema; emissão de gases do efeito estufa (GLAZ et al., 2016); e alto custo da rede devido à necessidade de afastar o sistema da região urbana à qual ele serve. Ademais, as lagoas de estabilização somente tratam as águas residuárias parcialmente, removendo o material orgânico e os patógenos, mas não os nutrientes. Portanto, seu efluente, a rigor, não pode ser descarregado em águas de superfície como costuma ser feito atualmente, visto que medidas como essa resultam na eutrofização dos corpos hídricos.

Um tratamento alternativo é a combinação de digestores anaeróbios, como o reator UASB (Upflow Anaerobic Sludge Blanket/Reator Anaeróbio de Manto de Lodo), com Lagoas de Polimento (LP). Van Haandel e Lettinga (1994), operando lagoas de polimento de fluxo contínuo (LPFC), mostraram que em termos de eficiência de remoção de material orgânico o reator UASB é superior à combinação de lagoa anaeróbia (LA) com lagoa facultativa (LF). A substituição desse sistema (LA+ LF) por um reator UASB apresenta muitas vantagens importantes, a saber: (1) a remoção do material orgânico no afluente do reator UASB é realizada em poucas horas, levando a uma redução da LPFC e diminuindo ainda mais as perdas por evaporação; (2) o biogás é coletado e pode ser queimado, evitando a liberação de metano para a atmosfera e a geração de maus odores; (3) o lodo pode ser descarregado em leitos de secagem e utilizado produtivamente como adubo e (4) com o odor em nível tolerável, abrese a possibilidade de operar o sistema próximo à região urbana. Conclui-se, portanto, que a combinação de reator UASB com LPFC elimina todos os grandes problemas de lagoas de estabilização convencionais bem como permite uma grande redução da área de tratamento e dos custos da rede de coleta.

Santos e van Haandel (2021a) mostraram que, no caso de um pré-tratamento anaeróbio eficiente em reator UASB, as lagoas de polimento podem ser operadas também em regime de bateladas sequenciais. Para as funções de remoção da matéria orgânica não há muita diferença entre as lagoas de polimento de bateladas sequenciais (LPBS) e as LPFC (ALBURQUERQUE, SANTOS e VAN HAANDEL, 2021), no entanto, para remoção de Escherichia coli (E.coli) as LPBS mostraram meIhores resultados em eficiência de remoção para um menor tempo de detenção hidráulica (TDH) (BATISTA et al., 2021). Em trabalhos anteriores, Santos, Santos e van Haandel (2021) e Santos e van Haandel (2021b) mostraram que a remoção eficiente e confiável dos nutrientes em LPBS é possível, enquanto em sistemas de LPFC essa remoção é parcial (ALBURQQUERQUU, SANTOS e VAN HAANDEL, 2021). Por essas razões, há claras vantagens na aplicação da LPBS em substituição à LPFC para o pós-tratamento do efluente do reator UASB.

Todavia, a aplicação do sistema UASB seguido de LPBS apresenta um problema: o fluxo de esgoto que passa pelo reator UASB é contínuo e as lagoas têm regime de bateladas. Uma possibilidade é operar uma série de LPBS com um volume igual à vazão diária de esgoto a ser tratado no reator, de tal forma que seja possível descarregar o efluente do UASB em uma destas LPBS, como mostra 
a Fig. 1A. Depois de cheia, o pós-tratamento se desenvolve na LPBS, removendo o material orgânico residual, os organismos patogênicos e, eventualmente, nitrogênio e fósforo por meio do aumento do $\mathrm{pH}$. Ao se construir um número de LPBS suficiente para realizar as funções que se deseja, pode-se encher as lagoas sequencialmente com efluente do UASB e descarregar o efluente final quando o tratamento desejado for alcançado. Logo depois da descarga do efluente final, a LPBS é utilizada para descarregar outra batelada de efluente do UASB.
Outra alternativa é a operação de uma lagoa de transbordo (LT), caracterizada por um tanque de equalização que se posiciona entre o reator UASB e a série de lagoas de polimento, conforme a Fig. 1B. A LT recebe continuamente o efluente do UASB e descarrega bateladas em cada uma das lagoas de polimento, enchendo-as imediatamente após a descarga do efluente final. Em função do rápido enchimento das LPBS devido à presença da $\mathrm{LT}$, o número $\mathrm{N}$ de lagoas será menor na configuração operada com LT.

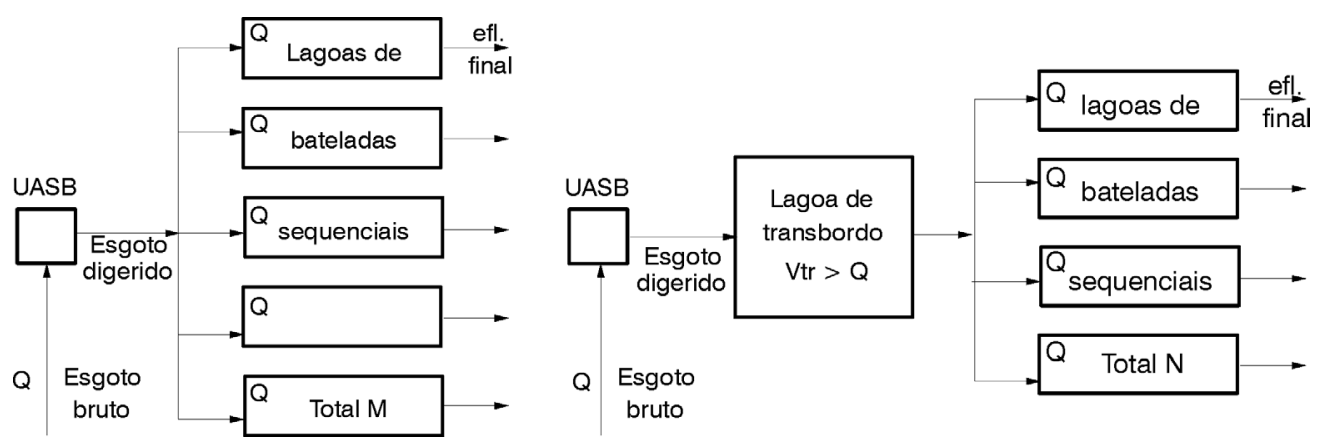

Figura 1 - Esquema da disposição e operação de lagoas de polimento alimentadas em regime de bateladas sequenciais sem (A) e com uma lagoa intermediária de transbordo (B)

No entanto, a LT não deve ser vista apenas como um tanque de equalização, uma vez que pode trazer diversas outras vantagens. A vantagem mais evidente é que a LT pode reter os sólidos sedimentáveis provenientes do reator UASB, cujo lodo tem de $1 / 3$ a $1 / 2$ de sua produção descarregado no efluente final, segundo Van Haandel e Van der Lubbe (2019). A retenção do lodo resulta numa redução da concentração da DBO descarregada nas LPBS. Assim, a carga orgânica nessas LPBS se reduz, facilitando o tratamento. Outros ganhos possíveis são a retenção de ovos de helmintos, a dessorção de $\mathrm{CO}_{2}$ da fase líquida e o início da produção de algas e oxigênio.

A retenção dos ovos de helmintos se baseia no mesmo processo de retenção de sólidos: a sedimentação simples na LT. A dessorção de $\mathrm{CO}_{2}$ reduz a acidez do efluente do reator UASB, que facilita o aumento do $\mathrm{pH}$ nas LP subsequentes. $\mathrm{O}$ oxigênio eventualmente produzido pode oxidar o sulfeto presente no efluente do UASB, eliminando parcial ou completamente a geração de odores que implica na sua melhor aceitação pela população contribuinte. Ademais, com a operação de uma LT abre-se a possibilidade de operar o reator UASB sem o separador de fases, retornando o lodo necessário para manter a massa máxima no reator UASB e descarregando o restante como lodo de excesso.

Em síntese, a LT atua na equalização das flutuações da qualidade do efluente digerido e facilita a operação das LPBS, uma vez que possibilita a atenuação de problemas como sobrecargas hidráulicas ou arraste de lodo que possam surgir 
nos digestores anaeróbios, impedindo que esses problemas cheguem às lagoas de polimento. No presente trabalho, relatam-se os resultados de uma investigação experimental efetuada em escala piloto e que avalia o desempenho das LT em função da sua profundidade e do TDH.

\section{METODOLOGIA}

\section{1 Área de estudo}

Os sistemas avaliados na presente pesquisa foram instalados e monitorados na Estação Experimental de Tratamento Biológico de Esgotos Sanitários (Extrabes), localizada na cidade de Campina Grande, Paraíba. O esgoto bruto utilizado na pesquisa foi proveniente de um condomínio residencial localizado na vizinhança das instalações da unidade experimental.

\subsection{Reator UASB e Lagoas de Transbordo}

Na presente pesquisa, o afluente foi digerido em um reator UASB, instalado e em operação no local de realização dos experimentos. $O$ reator foi projetado com um volume de $2,5 \mathrm{~m}^{3}$ e altura de $1,7 \mathrm{~m}$, com capacidade de receber vazão de até
$10 \mathrm{~m}^{3} / \mathrm{d}$ (SANTOS et al., 2016). Após a digestão, o efluente do UASB era então direcionado por bombeamento para as três lagoas de transbordo. Vale salientar que o reator, além de estável com lodo estabilizado, passou a ser operado sob carga máxima de biomassa sem a realização de descargas intencionais de lodo. Tal operação foi proposital, uma vez que se desejava analisar o desempenho das lagoas na função de decantadores secundários a fim de avaliar sua eficiência na remoção de sólidos.

$\mathrm{Na}$ Fig. 2 podem ser vistas as lagoas utilizadas com suas respectivas dimensões descritas na Tabela 1. As lagoas foram projetadas em escala piloto em material de fibra de vidro. As medidas de altura foram adotadas tendo em vista a operação do sistema em escala real. Desse modo, ao se estabelecer uma altura de 2,40 m vislumbrou-se a possibilidade de alimentação por gravidade do reator UASB para a $L T$, uma vez que normalmente um reator UASB possui de 4 a 6 m conforme a NBR 12.209/2011 (ABNT, 2011). Por outro lado, o valor da menor altura foi estabelecido tendo em vista a alimentação por gravidade da LT para as LPBS, dado que esta última normalmente possui $0,5 \mathrm{~m}$.

Tabela 1 - Parâmetros operacionais das lagoas de transbordo.

\begin{tabular}{|c|c|c|c|}
\hline Dimensões & $\mathbf{L T}_{1}$ & $\mathbf{L T}_{\mathbf{2}}$ & $\mathbf{L T}_{\mathbf{3}}$ \\
\hline Diâmetro $(\mathrm{m})$ & 0,47 & 0,75 & 0,50 \\
\hline Altura $(m)$ & 0,73 & 1,65 & 2,40 \\
\hline Volume $\left(\mathrm{m}^{3}\right)$ & 0,127 & 0,729 & 0,471 \\
\hline
\end{tabular}

* $\mathrm{LT}_{1}$ - Lagoa de Transbordo 1; $\mathrm{LT}_{2}$ - Lagoa de Transbordo 2; $\mathrm{LT}_{3}$ - Lagoa de transbordo 3.

Na Fig. 3 é apresentado um fluxograma da unidade de tratamento no qual se pode verificar desde a geração do esgoto no condomínio residencial, seguido por uma caixa de passagem em fibra de vidro na qual o esgoto bruto chegava por gravidade, garantindo, por sua vez, uma alimentação ininterrupta do reator UASB por meio do bombe- amento. $O$ reator UASB era operado com um TDH de $6 \mathrm{~h}$ com vazão constante. $O$ efluente do UASB passava por outro tanque, de onde era bombeado até as LT. As caixas de passagens possuíam uma agitação mecânica para garantir a homogeneização do esgoto e a suspensão dos sólidos sedimentáveis presentes. 


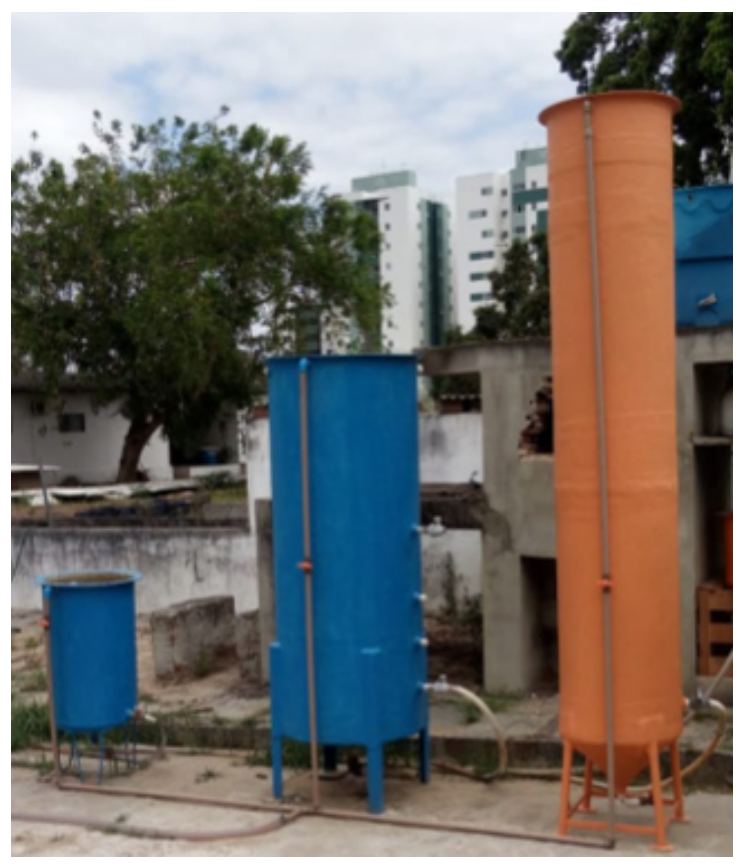

Figura 2 - Lagoas de transbordo utilizadas na pesquisa

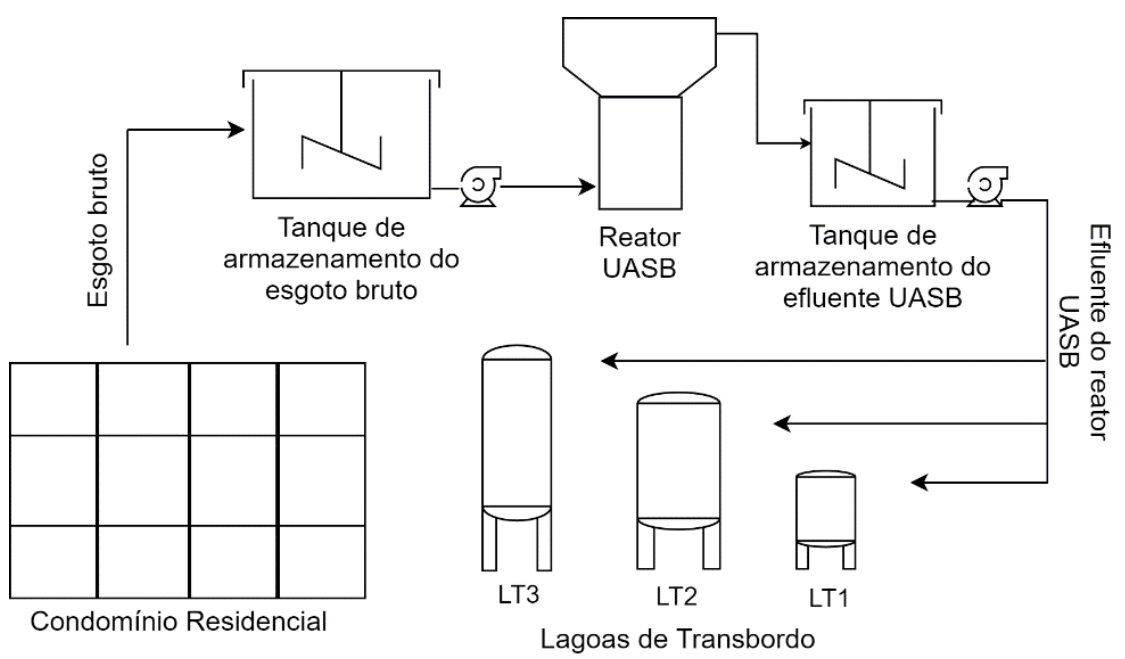

Figura 3 - Fluxograma do sistema de tratamento composto por reator UASB seguido de Lagoas de Transbordo

\subsection{Monitoramento e avaliação dos sistemas de tratamento}

A investigação experimental foi dividida em três fases com TDH de 3, 2 e 1,5 dias para $1^{\mathrm{a}}, 2^{\mathrm{a}}$ e $3^{\mathrm{a}}$ fase, respectivamente. A adoção do tempo máximo de 3 dias foi baseada nos custos de construção, enquanto o TDH mínimo de 1,5 dias foi escolhido no intuito de manter um residual como inóculo na LT.
O monitoramento do desempenho do sistema foi realizado por meio de análises físico-químicas do efluente do reator UASB e das lagoas de transbordo. O período de monitoramento dos sistemas ocorreu de setembro de 2018 a junho de 2019. As análises físico-químicas foram realizadas com frequência de duas vezes semanais, no período da manhã, com coleta das amostras efetuadas por volta das 8 horas, todas de acordo com os méto- 
dos padrões estabelecidos pelo Standard Methods (APHA, 2012). A exceção diz respeito aos ovos de helmintos, cuja metodologia aplicada foi de Bailenger modificado (AYRES e MARA, 1996). A concentração de $\mathrm{CO}_{2}$ e a acidez foram calculadas a partir da determinação da alcalinidade e do $\mathrm{pH}$. Para a alcalinidade, utilizou-se a técnica Titulométrica com potenciômetro pelo método de Kapp (KAPP, 1984). As coletas foram realizadas em recipientes utilizados para receber o efluente descarregado após o fim de uma batelada. Antes da amostragem, o material era homogeneizado de modo que uma mesma amostra era utilizada para a análise de todos os parâmetros. As medidas de oxigênio dissolvido foram realizadas pela técnica respirométrica (HAANDEL e CATUNDA, 2013) para o efluente final.

\subsection{Determinação da dessorção de $\mathrm{CO}_{2}$ e acidez}

Para avaliar o desempenho de dessorção em termos de eficiência de remoção de $\mathrm{CO}_{2}$ deve-se comparar a dessorção observada com a máxima teórica possível. Para tanto, precisa-se saber primeiramente a concentração de saturação de $\mathrm{CO}_{2}$ em água que está em contato com o ar. $\mathrm{O}$ método para determinar a concentração para valores medidos da alcalinidade e do $\mathrm{pH}$ foi discutido em publicação anterior (SANTOS e VAN HAANDEL, 2021b). Na Fig. 4 pode-se observar a curva de equilíbrio ar-água no diagrama de Deffeyes.

O diagrama de Deffeyes se baseia na constatação de que para qualquer valor do $\mathrm{pH}$ existe uma relação linear entre a alcalinidade e a acidez de uma água. A eficiência da dessorção do $\mathrm{CO}_{2}$ no efluente do UASB é estimada da seguinte maneira:

(1) Pode-se traçar um conjunto de retas ligando a acidez à alcalinidade para diferentes valores, como na Fig. 4;

(2) Na mesma figura, plota-se a curva de saturação de $\mathrm{CO}_{2}$ para o equilíbrio ar-água;
(3) Determinam-se a alcalinidade e o pH no efluente do UASB e no efluente da LT (pontos A e $B$, respectivamente).

Para o valor inicial da alcalinidade e do $\mathrm{pH}$ (ponto A), determina-se a acidez do equilíbrio ar-água correspondente (ponto $\mathrm{C}$ ).

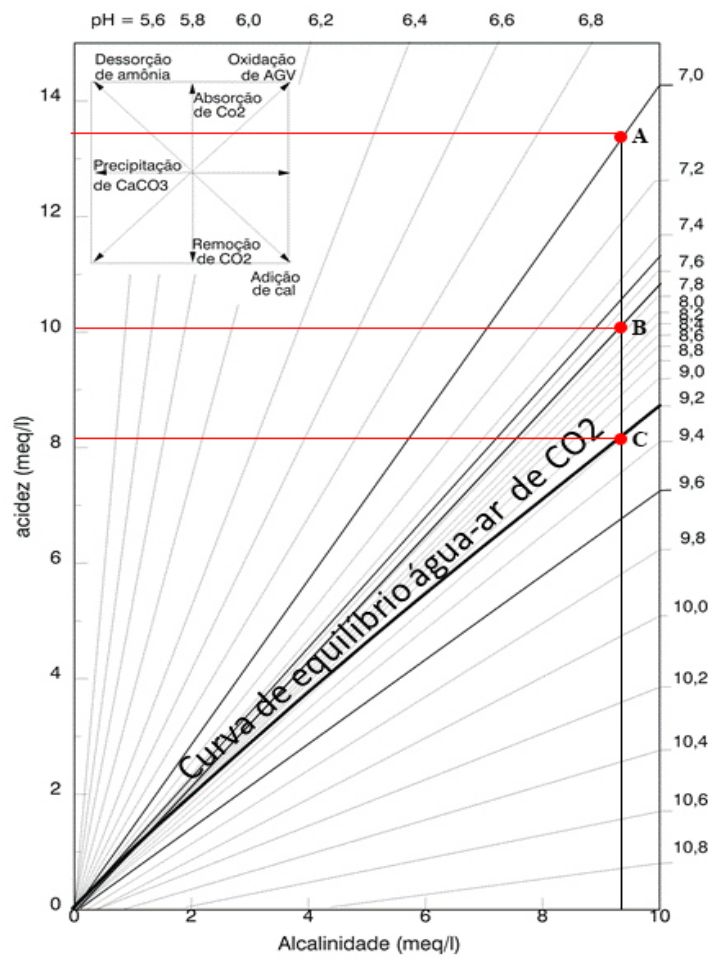

Figura 4 - Diagrama de Deffeyes para temperatura de $25^{\circ} \mathrm{C}$. Fonte: Adaptado de Cavalcanti, 2009

Em seguida, calcula-se a eficiência da dessorção pela razão entre a variação da acidez observada e a variação teórica possível, como descrito pela Eq. 1.

$\mathrm{E}_{\mathrm{CO2}}=\Delta \mathrm{Ac}_{\mathrm{AB}} / \Delta \mathrm{Ac}_{\mathrm{AC}}$

Em que:

$\mathrm{E}_{\mathrm{CO} 2}=$ eficiência da dessorção de $\mathrm{CO}_{2}$

$\Delta \mathrm{Ac}_{\mathrm{AB}}$ = variação observada da acidez (deslocamento do ponto A para B)

$\Delta \mathrm{Ac}_{\mathrm{AC}}=$ variação teórica possível (deslocamento do ponto A para C) 


\subsection{Análise estatística}

A estatística descritiva foi realizada para todos os dados analisados, de forma a proporcionar medidas de tendência central e medidas de dispersão, utilizando-se a ferramenta "boxplot" para gerar gráficos que possibilitem uma melhor visualização da série de dados do período experimental. Para essas análises estatísticas foram utilizados os softwares Microsoft Excel (2016) e Statistica (2010). Foi realizada uma análise de variância (Anova) e o Teste Tukey, com nível de significância de $5 \%$, ambos realizados por meio do software Past (2019), para os parâmetros de DQQ , sólidos, sulfeto e dessorção de $\mathrm{CO}_{2}$. Esses testes foram efetuados com os dados de eficiência e concentrações a fim de verificar quais dados apresentaram diferenças significativas, correlacionando essa informação às diferentes alturas e TDH.

\section{RESULTADOS E DISCUSSÃO}

\subsection{Caracterização geral do efluente do reator UASB}

O reator UASB já se encontrava em funcionamento e operando em condições estacionárias. $\mathrm{Na}$ Tabela 2 são apresentadas as características do esgoto utilizado na pesquisa. Nota-se que, apesar de a remoção de sólidos e matéria orgânica serem consideráveis, faz-se necessário um pós-tratamento desse efluente devido à elevada concentração de sólidos suspensos ainda presente no efluente final.

Tabela 2 - Concentrações médias dos dados analisados do afluente e efluente do reator UASB, em nível de caracterização destes.

\begin{tabular}{|c|c|c|c|}
\hline Parâmetros (mg/L) & Esgoto Bruto & UASB & Eficiência de remoção \\
\hline $\mathrm{DQO}_{b}$ & 930 & 516 & $45 \%$ \\
\hline $\mathrm{DQO}_{d}$ & 930 & 344 & $63 \%$ \\
\hline SST & 471 & 154 & --- \\
\hline SSV & 400 & 108 & --- \\
\hline SSF & 71 & 42 & --- \\
\hline $\mathrm{pH}$ & 7,3 & 7,2 & --- \\
\hline Amônia & 89 & 96 & --- \\
\hline Fósforo Total & 10 & 8 & $17 \%$ \\
\hline
\end{tabular}

"DQO - Demanda Química de Oxigênio bruta; DQQD - Demanda Q⿱uímica de Oxigênio decantada; SST - Sólidos Suspensos Totais; SSV - Sólidos Suspensos Voláteis; SSF - Sólidos Suspensos Fixos.

\subsection{Desempenho das Lagoas de Transbordo}

Na Tabela 3 podem ser observadas as concentrações médias dos parâmetros analisados afluente e efluente às lagoas.

A remoção de sólidos nas lagoas de transbordo foi uma das principais vantagens evidenciadas, constatando-se elevado desempenho em todas as fases e alturas analisadas. As lagoas apresentaram eficiências médias para os sólidos suspensos totais de $37 \%, 57 \%$ e $59 \%$ na primeira fase; $56 \%, 71 \%$ e $71 \%$ na segunda; e $46 \%$, $49 \%$ e $49 \%$ na terceira, para a $\mathrm{LT}_{1}, \mathrm{LT}_{2}$ e $\mathrm{LT}_{3}$, respectivamente.
Da mesma forma, bons desempenhos foram observados para as frações de sólidos voláteis, com eficiências médias de $32 \%$, 52\% e $58 \%$ na primeira fase; $61 \%$, $80 \%$ e $78 \%$ na segunda; e $47 \%$, $56 \%$ e $51 \%$ na terceira, na mesma ordem, para a $\mathrm{LT}_{1}$, $\mathrm{LT}_{2}$ e $\mathrm{LT}_{3}$.

Observou-se um ligeiro aumento da concentração de sólidos totais e totais voláteis na $\mathrm{LT}_{1}$ nas duas primeiras fases comparado com a $\mathrm{LT}_{2}$ e $\mathrm{LT}_{3}$, possivelmente em razão da maior concentração de algas, a ser descrita mais adiante. Por outro lado, a maior eficiência evidenciada 
da segunda fase se deu por conta de uma maior expulsão de sólidos do reator UASB, tendência que pode ser observada nas Fig. 5 e 6 para os sólidos totais e totais voláteis, respectivamente. Observa-se também nesses gráficos uma maior dispersão dos dados de concentração do efluente UASB, demonstrando a boa capacidade das lagoas de transbordo em receber choques de carga ou hidráulicos, que eventualmente são responsáveis por um maior arraste de sólidos nos reatores UASB (RAMOS, 2008; CHERNICHARO, 2018).

Tabela 3 - Concentração média dos dados analisados para o efluente UASB e efluente das lagoas, nas três fases experimentais.

\begin{tabular}{|c|c|c|c|c|c|c|c|c|c|c|c|c|}
\hline \multirow{2}{*}{ Parâmetros } & \multicolumn{4}{|c|}{$1^{\text {a }}$ Fase } & \multicolumn{4}{|c|}{$2^{a}$ Fase } & \multicolumn{4}{|c|}{$3^{a}$ Fase } \\
\hline & UASB & $\mathrm{LT}_{1}$ & $\mathbf{L T}_{2}$ & $\mathrm{LT}_{3}$ & UASB & $\mathrm{LT}_{1}$ & $\mathbf{L T}_{2}$ & $\mathrm{LT}_{3}$ & UASB & $\mathrm{LT}_{1}$ & $\mathbf{L T}_{2}$ & $\mathbf{L T}_{3}$ \\
\hline $\mathrm{SST}$ (mg/L) & 129 & 79 & 51 & 48 & 208 & 73 & 48 & 49 & 125 & 58 & 59 & 57 \\
\hline $\mathrm{SSV}$ (mg/L) & 81 & 52 & 35 & 29 & 151 & 49 & 27 & 29 & 96 & 42 & 39 & 41 \\
\hline $\mathrm{DQO}_{\mathrm{b}}(\mathrm{mg} / \mathrm{L})$ & 531 & 273 & 216 & 208 & 592 & 254 & 234 & 230 & 522 & 280 & 296 & 283 \\
\hline $\mathrm{DQO}_{\mathrm{d}}(\mathrm{mg} / \mathrm{L})$ & 379 & 217 & 201 & 196 & 365 & 230 & 227 & 218 & 322 & 257 & 272 & 277 \\
\hline $\mathrm{OH}\left(\mathrm{n}^{\circ} \mathrm{OH} / \mathrm{L}\right)$ & 69 & 5 & 5 & 2 & 287 & 6 & 7 & 3 & 207 & 7 & 9 & 8 \\
\hline Sulfeto (mg/L) & 11 & 1 & 4 & 4 & 13 & 4 & 9 & 6 & 14 & 5 & 11 & 9 \\
\hline $\mathrm{OD}(\mathrm{mg} / \mathrm{L})$ & -- & 0,99 & 0,50 & 0,41 & -- & 0,41 & 0,36 & 0,32 & -- & 0,31 & 0,25 & 0,23 \\
\hline Clorofila $a(\mu \mathrm{g} / \mathrm{L})$ & -- & 160 & 242 & 83 & -- & 322 & 46 & 10 & -- & 167 & 29 & 15 \\
\hline $\mathrm{CO}_{2}(\mathrm{meq} / \mathrm{L})$ & 1,3 & 0,3 & 0,4 & 0,4 & 1,7 & 0,4 & 0,8 & 0,7 & 2,2 & 0,8 & 1,2 & 1,0 \\
\hline Acidez (meq/L) & 11,8 & 9,6 & 10,3 & 10,5 & 12,3 & 9,8 & 11,1 & 10,6 & 14,2 & 11,0 & 12,0 & 11,6 \\
\hline
\end{tabular}

*OH - Ovos de Helmintos; OD - Oxigênio Dissolvido.

Segundo a literatura (FORESTI et al., 2006; van HAANDEL et al., 2006; van HAANDEL et al., 2015; van HAANDEL e van der LUBBE, 2019), os reatores UASB, especialmente quando submetidos à máxima biomassa possível, expulsam uma quantidade considerável de sólidos que comprometem a qualidade do efluente final. Deste modo, há a necessidade de um dispositivo de separação mais eficiente, o que pode ser realizado por LT. Uma vez que os dados demonstram uma alta eficiência das lagoas na função de decantadores secundários e não apresentam diferenças expressivas nos valores em relação ao TDH, conclui-se que o menor TDH investigado (1,5 d) já seria suficiente para a sedimentação dos sólidos suspensos mesmo para a maior profundidade.

No tocante à eficiência média de remoção de DQQO decantada, a primeira fase apresentou valores de $43 \%$, $50 \%$ e $51 \%$, respectivamente para $\mathrm{LT}_{1}, \mathrm{LT}_{2}$ e $\mathrm{LT}_{3}$. Na segunda fase, as eficiências foram de $36 \%, 36 \%$ e $40 \%$, respectivamente, para $\mathrm{LT}_{1}, \mathrm{LT}_{2}$ e $\mathrm{LT}_{3}$. Por fim, na terceira fase foram encontrados valores consideravelmente menores em razão do baixo TDH, de $20 \%, 15 \%$ e $14 \%$. Por sua vez, a eficiência média para DQO bruta na primeira fase foi de $45 \%$, $54 \%$ e $55 \%$; na segunda fase foi de $51 \%$, $55 \%$ e $56 \%$; e na terceira fase de $39 \%$, $33 \%$ e $36 \%$, referentes a $L T_{1}, L_{2}$ e $L T_{3}$, respectivamente.

A partir da análise e da comparação entre os dados de DQO bruta e decantada, observou-se que havia uma considerável diferença entre esses valores para o efluente do UASB. Em contraste, a diferença entre a DQO bruta e decantada do efluente das lagoas de transbordo era pequena, o que evidencia a eficiente sedimentação dos sólidos expulsos do reator UASB nas lagoas de transbordo, ratificando os dados já apresentados de variação dos sólidos totais.

Apesar de ter sido observada uma eficiência ligeiramente menor na $\mathrm{LT}_{1}$ da primeira fase, os valores da DQQ não apresentaram diferenças significativas com relação à variação da altura das lagoas, resultado demostrado adiante na análise estatística. 
No gráfico da Fig. 7 percebe-se uma diminuição da eficiência de remoção da DQQ da primeira para a terceira fase, bem como alguns outliers que se devem possivelmente a erros analíticos. As variações e dispersões dos dados do reator e das lagoas são semelhantes e resultam das oscilações normais existentes em sistemas biológicos.

Vale destacar as instabilidades operacionais dos reatores UASB às quais este trabalho esteve sujeito, em consonância com os demais estudos de mesma natureza. Instabilidades ocasionadas por eventuais sobrecargas hidráulicas podem aumentar a passagem de lodo de excesso ou mesmo incluir esgoto bruto ao efluente final (COURAS et al., 2014; CAVALCANTI, 2009; RAMOS, 2008; CHERNICHARO, 2018). Como observado, as elevações da DQQO bruta em função do lodo de excesso não prejudicaram o efluente das lagoas de transbordo, demonstrando a importância de que estas estejam inseridas antes das lagoas de polimento a fim de reterem eventuais instabilidades do digestor anaeróbio.

Instabilidades hidráulicas poderiam ser solucionadas com a adoção de tanques de equalização antes e depois do reator UASB; contudo, é mais vantajoso inserir outra unidade operacional que possibilita não apenas a eliminação desse problema como também proporciona o melhoramento do efluente sobre outros aspectos.

De forma semelhante aos sólidos, as lagoas apresentaram ótima remoção de ovos de helmintos nas três fases, com mais de $90 \%$ de eficiência, uma vez que o mecanismo de remoção desses também é a sedimentação. As espécies detectadas foram Ascaris lumbricoides, Ancylostoma sp. e Enteróbius vermiculares, com predominância de Ancylostoma sp., seguido por Ascaris lumbricoides e por fim Enteróbius vermiculares. Justifica-se a maior predominância dos Ancylostoma sp. em função da sua menor velocidade de sedimentação, de aproximadamente $0,39 \mathrm{~m} / \mathrm{h}$, fator que torna sua remoção mais difícil (KONATÉ et al., 2013). Esses dados convergem com os estudos de Konaté et al. (2013), que ao analisar um sistema de lagoas convencionais também observaram no esgoto bruto a presença de Acaris lumbricoides, Ancylostoma sp., bem como de T. trichiura e Trichostrongylus sp. Os autores constataram uma maior remoção na lagoa anaeróbia das duas últimas espécies, enquanto Ascaris lumbricoides foram persistentes até as lagoas facultativas e Ancylostoma sp. até a lagoa de maturação. Contudo, a remoção completa dos ovos de helmintos só foi observada no efluente da lagoa de maturação após um TDH de 18 dias.

Foi observada uma ótima eficiência da $\mathrm{LT}_{1}$ na remoção de sulfeto nas três fases com eficiências de remoção de $95 \%, 73 \%$ e $64 \%$ nas fases 1, 2 e 3 , respectivamente. Porém, nas demais lagoas observou-se apenas remoção parcial. Na primeira fase, as eficiências foram de $59 \%$ e $60 \%$, para $\mathrm{LT}_{2}$ e $\mathrm{LT}_{3}$, nessa ordem; na segunda fase obteve-se $30 \%$ na $\mathrm{LT}_{2}$ e $48 \%$ na $\mathrm{LT}_{3}$; e na última fase a eficiência caiu para $23 \%$ na $\mathrm{LT}_{2}$ e $39 \%$ na $\mathrm{LT}_{3}$. As eficiências apresentaram uma redução com a diminuição do TDH, dados também apresentados na Fig. 8. A análise estatística realizada confirmou que houve diferença significativa entre a primeira fase e as demais, bem como entre a $\mathrm{LT}_{1}$ e as demais lagoas. Desse modo, pode-se afirmar que não houve influência das alturas da $\mathrm{LT}_{2}$ e da $\mathrm{LT}_{3}$ sobre o desempenho, bem como não houve diferença significativa entre os TDH de 2 e 1,5 dias para $\mathrm{LT}_{2}$ e $\mathrm{LT}_{3}$. O melhor desempenho da $\mathrm{LT}_{1}$ da primeira fase deve-se a duas possíveis razões: melhores condições superficiais de OD e a possível presença da bactéria Thiopedia, discutida adiante para os dados de clorofila $a$. Em ambos os casos há o favorecimento da oxidação biológica do sulfeto por vias distintas. No primeiro caso ocorre a oxidação aeróbia e, no segundo, oxidação anóxica. Nas demais lagoas, apesar de apresentarem profundidades diferentes, as concentrações de clorofila $a$ e OD foram semelhantes, concluindo-se, desta forma, que nessas duas lagoas a diferença de altura não foi suficiente para provocar grandes mudanças no seu desempenho. 
Duas fontes possíveis de OD nas lagoas podem ser elencadas: primeiro, a produção pelas algas e, segundo, pela absorção de oxigênio por meio da interface líquido/atmosfera. Segundo Cavalcanti (2009), há uma tendência natural de transferência de oxigênio do ar para a lagoa quando esta se encontra com a concentração de oxigênio inferior à de saturação, como foi o caso das lagoas de transbordo analisadas. Essa absorção é maior quanto maior o tempo e quanto menor a altura.

Cavalcanti (2009) chegou à conclusão de que a absorção de oxigênio em LP é insignificante, uma vez que nessas unidades há uma alta produção de oxigênio das algas, levando as lagoas a níveis maiores da saturação. Contudo, para as lagoas em questão (LT), a absorção pode ser considerada, visto que as concentrações de OD não foram superiores a $1 \mathrm{mg} / \mathrm{L}$.

Houve considerável remoção de $\mathrm{CO}_{2}$ nas três fases experimentais. No efluente do UASB há predominância da dessorção, devido ao fato de o efluente estar em equilíbrio com o biogás, isto é, supersaturado de $\mathrm{CO}_{2}$. Segundo van Haandel e van der Lubbe (2019), a taxa de dessorção depende do gradiente de concentração (água-ar), ou seja, do grau de supersaturação. Deste modo, quando o meio está supersaturado há um desprendimento do gás para a atmosfera até que se atinja um equilíbrio ou saturação. Foram constatadas, portanto, eficiências médias de $80 \%$, 67\% e 64\%, respectivamente para $\mathrm{LT}_{1}, \mathrm{LT}_{2}$ e $\mathrm{LT}_{3}$ na primeira fase. Na segunda fase, houve uma remoção média na $\mathrm{LT}_{1}, \mathrm{LT}_{2}$ e $\mathrm{LT}_{3}$ de $72 \%$, $46 \%$ e $58 \%$, nessa ordem. Por fim, na terceira fase, as eficiências médias de remoção foram de $59 \%$, $42 \%$ e $50 \%$, respectivamente para $\mathrm{LT}_{1}, \mathrm{LT}_{2}$ e $\mathrm{LT}_{3}$.

As maiores eficiências de $\mathrm{CO}_{2}$ observadas nos maiores TDH e menores alturas devem-se à maior taxa de transferência de oxigênio (MORAIS, SANTOS e VAN HAANDEL, 2021). Na Fig. 9 pode-se observar uma menor dispersão dos dados das lagoas comparados aos valores do reator
UASB, pois a faixa de variação dos dados é menor após a dessorção do $\mathrm{CO}_{2}$. Ademais, nesse estágio não há absorção de $\mathrm{CO}_{2}$ pois, apesar da ótima dessorção, em nenhum caso foi atingido o ponto de equilíbrio de saturação de 0,01 meq/L.

Considerando somente a dessorção de $\mathrm{CO}_{2}$, sem interferências de outros processos que podem ocorrer na LT, a alcalinidade seria constante e a acidez reduziria na proporção estequiométrica de 2 (100 mg $\mathrm{CaCO}_{3}$ ) por mol de $\mathrm{CO}_{2}$ removido (CAVALCANTI, 2009). E, conforme apresentado na Tabela 3, houve uma redução da acidez proporcional à dessorção de $\mathrm{CO}_{2}$.

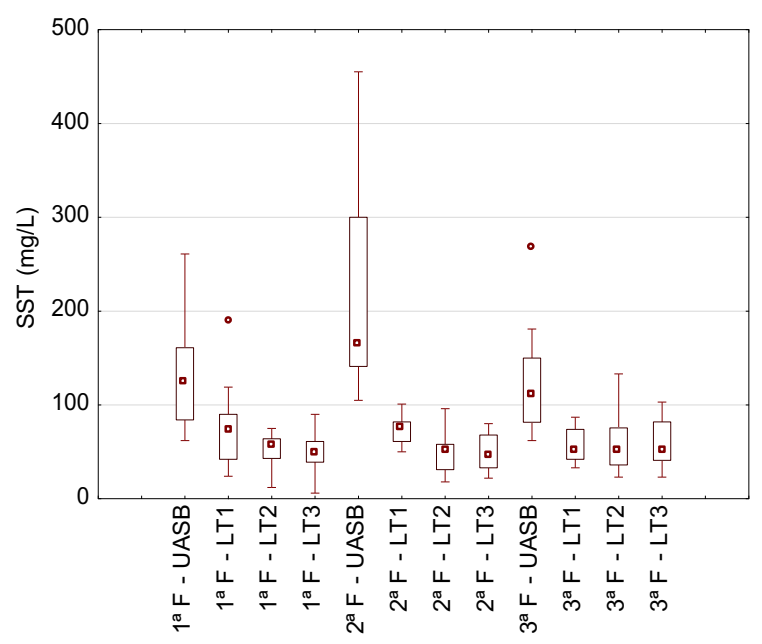

Figura 5 - Sólidos Suspensos Totais (mg/L) das três lagoas, nas diferentes fases

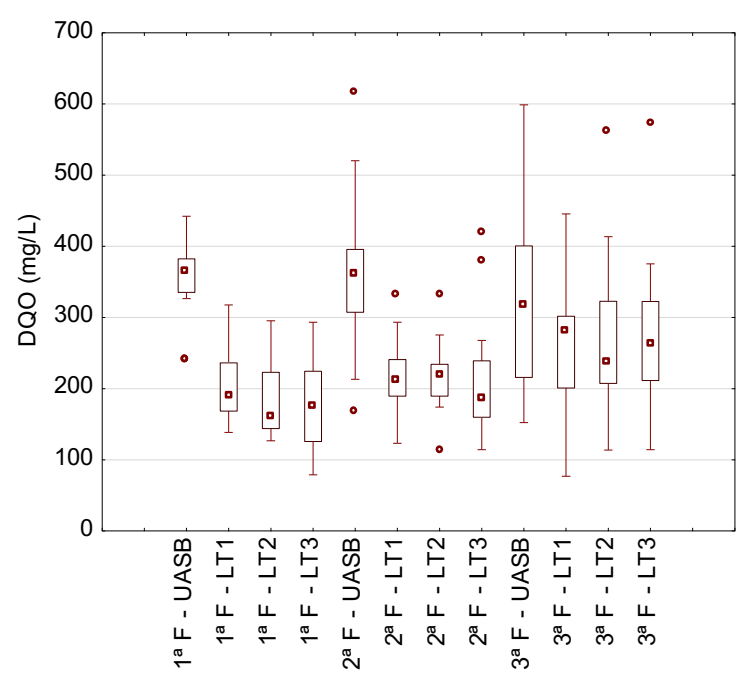

Figura 6 - Sólidos Suspensos Voláteis (mg/L) das três lagoas, nas diferentes fases 


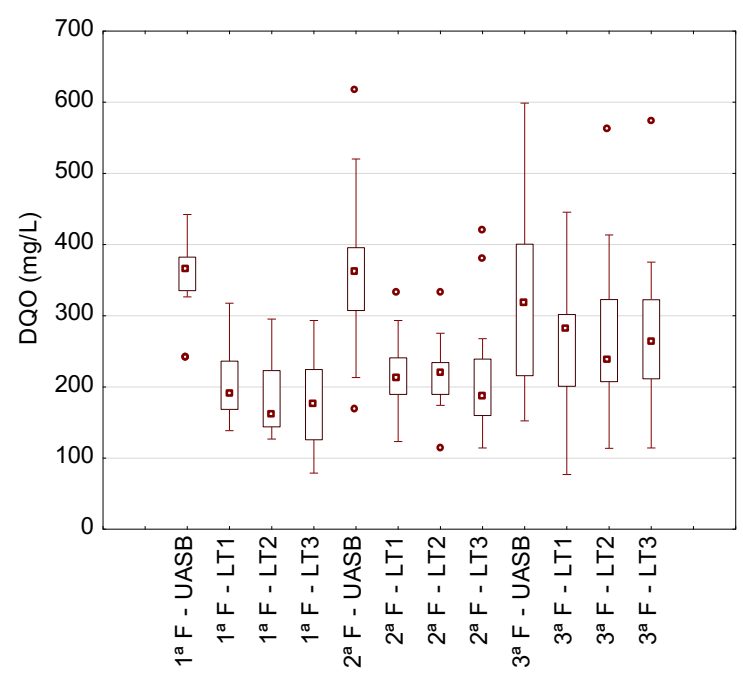

Figura 7 - Concentrações de DQQO (mg/L) do reator UASB e das lagoas nas três diferentes fases experimentais

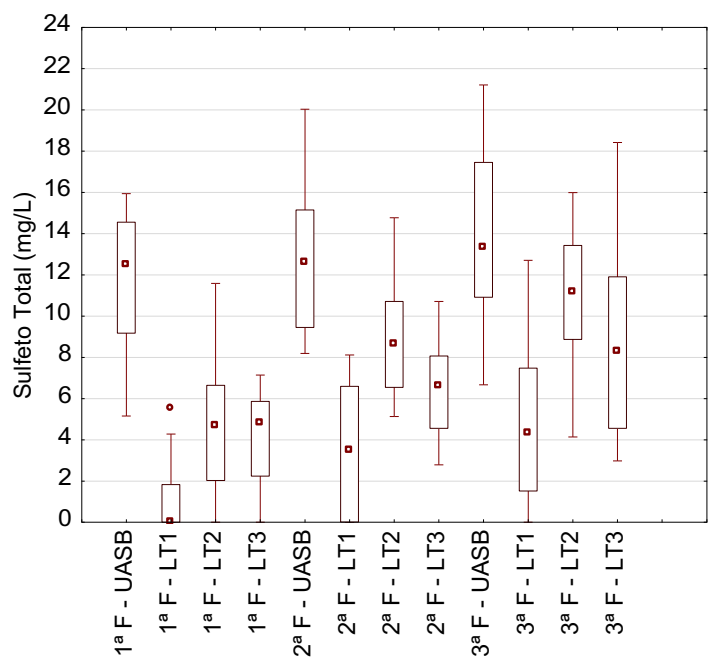

Figura 8 - Concentrações de Sulfeto Total (mg/L) do reator UASB e das lagoas nas três diferentes fases experimentais

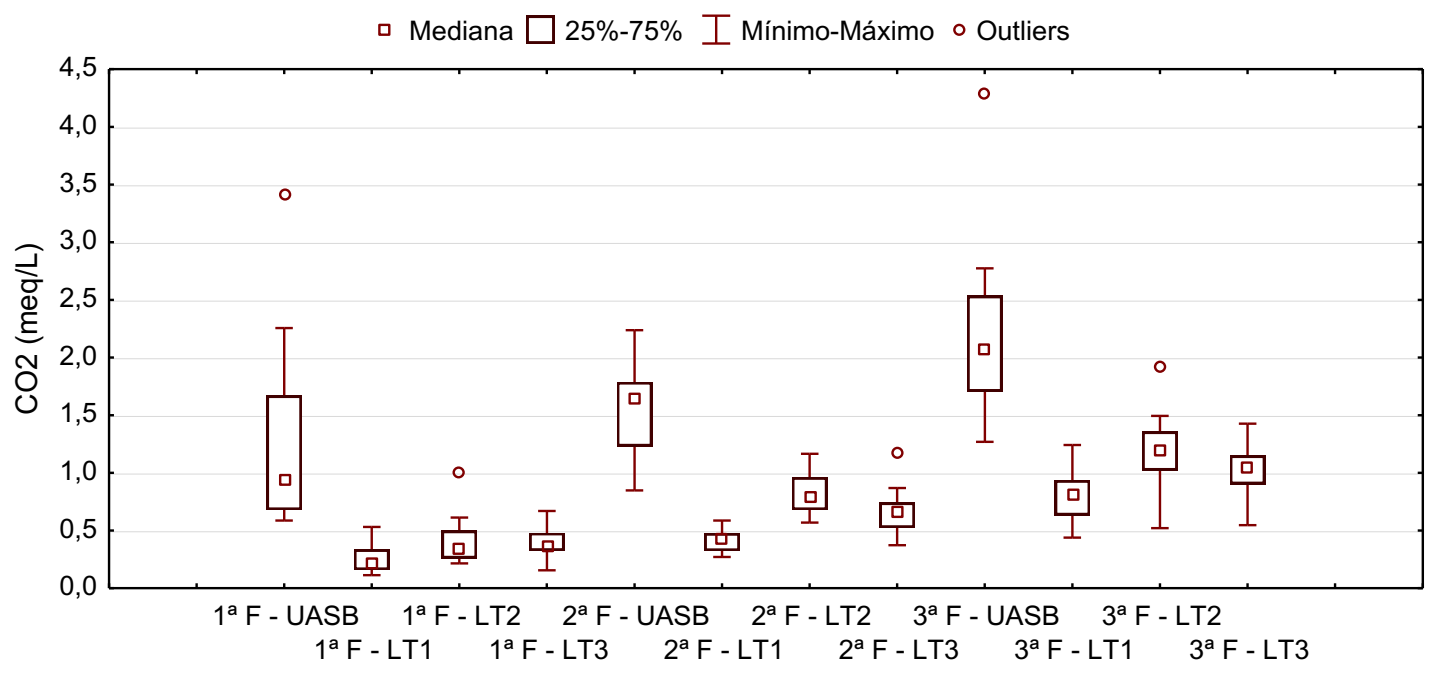

Figura 9 - Concentração de $\mathrm{CO}_{2}$ em meq/L, nas três diferentes fases e nas três lagoas

A clorofila a média da primeira fase foi de 160 , 242 e $83 \mu \mathrm{g} / \mathrm{L}$ para $\mathrm{LT}_{1}, \mathrm{LT}_{2}$ e $\mathrm{LT}_{3}$, respectivamente. A menor média da $L T_{1}$ deve-se, possivelmente, à proliferação de um tipo de bactéria fotoautotrófica de pigmentação característica (púrpura/avermelhada) que inibe o desenvolvimento adequado das algas verdes. A medida tomada para redução dessas bactérias a níveis não detectáveis visivelmente foi o esvaziamento e limpeza da $\mathrm{LT}_{1}$, na semana do dia 01 de fevereiro de 2019, o que proporcionou em seguida um rápido aumento das algas verdes. Esses dados podem ser observados nas Fig. 10, 11 e 12. 


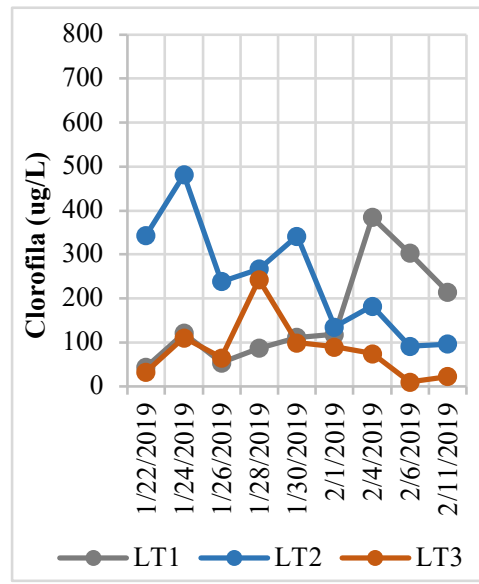

Figura 10 - Clorofila a da primeira fase

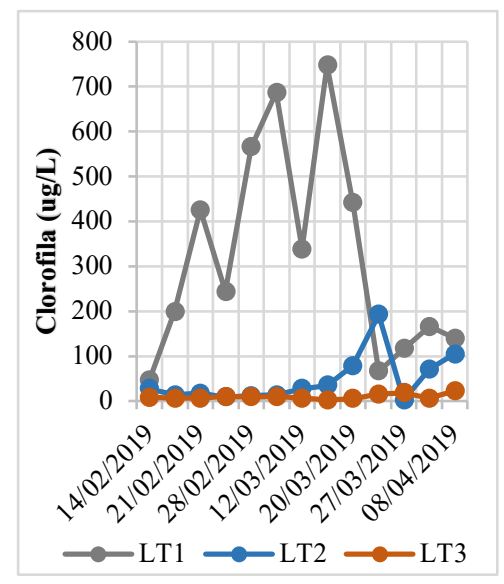

Figura 11 - Clorofila a da segunda fase

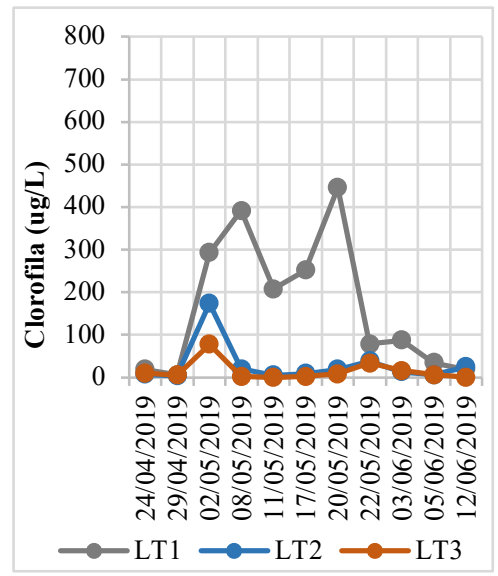

Figura 12 - Clorofila a da terceira fase

Van Haandel (2001), em parecer técnico referente ao sistema integrado de esgotos domésticos e industriais de Fortaleza-CE realizado para es- tabelecer a razão da cor avermelhada das lagoas de estabilização, chegou à conclusão de que esse fato se devia à proliferação de um gênero específico de bactérias púrpuras fotoautotróficas, as Thiopedia. Essas bactérias utilizam sulfeto como substrato (usando esse elemento como doador de elétrons para reduzir o dióxido de carbono, quando há energia da luz solar). As condições ambientais favoráveis para sua predominância são: alta concentração de sulfato e sulfeto; $\mathrm{pH}$ elevado e, principalmente, baixa produção de biogás, que favorece a predominância do sulfeto na fase líquida; digestão anaeróbia deficiente, que leva a uma concentração elevada de material biodegradável no afluente da lagoa (VAN HAANDEL, 2001).

Na segunda fase, a concentração de clorofila a da $L T_{1}$ continuou elevada, enquanto na $L T_{2}$ e $L T_{3}$ houve uma redução considerável. A média dessas concentrações foi de 322 , 46, e $10 \mu \mathrm{g} / \mathrm{L}$ para a $L T_{1}, L T_{2}$ e $L T_{3}$, respectivamente. Na última fase, a clorofila a da $\mathrm{LT}_{1}$ diminuiu, passando a uma média de $167 \mu \mathrm{g} / \mathrm{L}$. Esse fato pode ser justificado pela diminuição do tempo de incidência solar, apesar de não ter sido observada a mesma evidência na primeira fase para a lagoa $L_{1}$, visto que houve a predominância de possíveis bactérias fotoautotróficas. Para $\mathrm{LT}_{2}$ e $\mathrm{LT}_{3}$, na terceira fase observaram-se concentrações de clorofila não muito diferentes da segunda fase, com médias de $29 \mu \mathrm{g} / \mathrm{L}$ e $15 \mu \mathrm{g} / \mathrm{L}$.

\subsection{Análise estatística}

Os testes de variância (Anova) e Tukey para os dados de desempenho da DQQ não apresentaram diferenças significativas em relação à altura, uma vez que o teste apresentou um valor de $p$ maior que $0,05(5 \%)$, rejeitando a hipótese nula de que a remoção de DQQ é influenciada pela altura da LT. Em relação ao TDH (as três fases distintas), o valor de $p$ foi menor do que 0,05 , 
apresentando diferença significativa e indicando influência do TDH no desempenho da LT na remoção de DQO. Essa diferença foi especificamente entre a $1^{\mathrm{a}}$ e $3^{\mathrm{a}}$ fase e entre a $2^{\mathrm{a}}$ e $3^{\mathrm{a}}$ fase para todas as lagoas, comportamento que se justifica pelo baixo desempenho da $3^{a}$ fase, como pode ser verificado na Fig. 13.

O resultado das análises de variância (Anova) e Tukey para os dados de sólidos atestou uma diferença significativa entre as concentrações de sólidos totais e totais voláteis na $\mathrm{LT}_{1}$ das duas primeiras fases em comparação à $\mathrm{LT}_{2} \mathrm{e} \mathrm{LT}_{3}$. Uma vez que o teste acusou valores de $p$ menores do que 0,05 (5\%), admite-se a hipótese nula de que a remoção de sólidos é influenciada pela altura da lagoa $L T_{1}$ na primeira e na segunda fase. As demais interações não acusaram diferença significativa (valores de $p>0,05$ ) como mostra-se nas Fig. 14A e 14B. Desse modo, ratifica-se que não há influência do TDH sobre a remoção de sólidos.

Para os dados de sulfeto, os testes da Anova e Tukey não acusaram diferença significativa entre a $2^{\mathrm{a}}$ e $3^{\mathrm{a}}$ fase, bem como não houve diferença significativa entre a $\mathrm{LT}_{2}$ e $\mathrm{LT}_{3}$, como pode ser observado na Fig. 15A. Analogamente, o teste Tukey para o desempenho de $\mathrm{CO}_{2}$ não apresentou diferença significativa entre a $2^{\mathrm{a}}$ e $3^{\mathrm{a}}$ fase, bem como não houve diferença significativa entre as lagoas $\mathrm{LT}_{2}$ e $\mathrm{LT}_{3}$ em todas as fases. Nesse último caso, porém, também não foram encontradas diferenças significativas entre $L T_{1}$ e $L T_{2}$ para $1^{\mathrm{a}}$ e $3^{\mathrm{a}}$ fase, como pode ser observado na Fig. 15B.

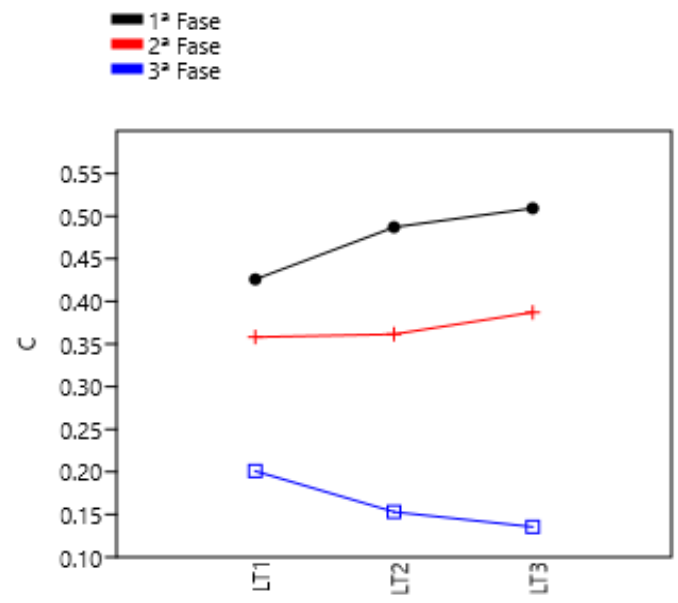

Figura 13 - Representação gráfica do teste de Tukey, com representação de $\mathrm{C}$ do desempenho médio das lagoas em cada fase em relação a DQQO
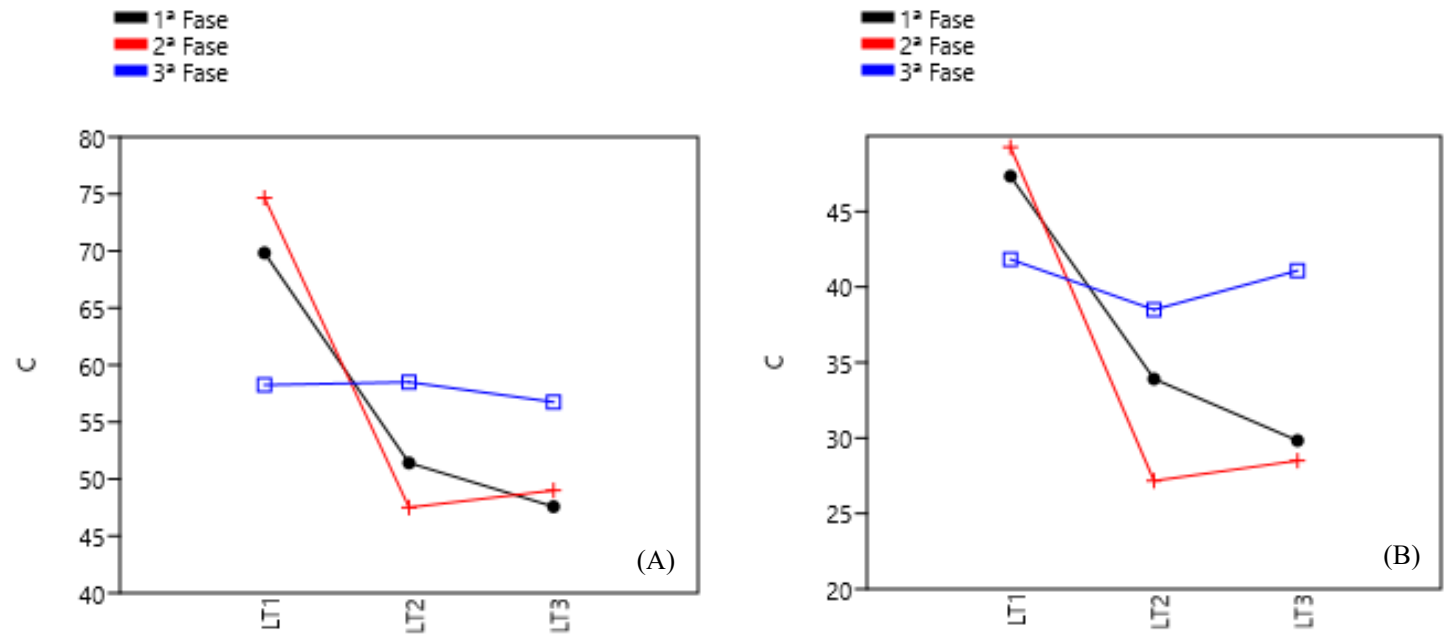

Figura 14 - Representação gráfica do teste de Tukey para as concentrações médias dos SST (A) e para as concentrações médias dos SSV (B) 

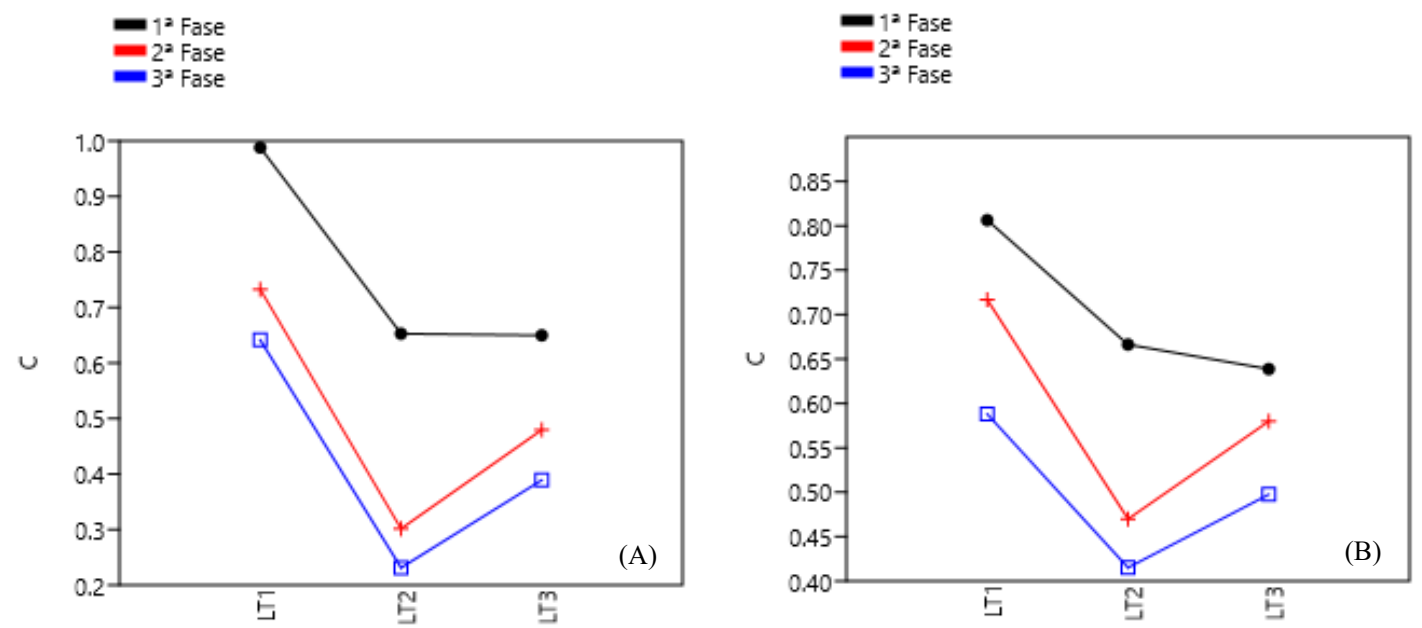

Figura 15 - Representação gráfica do teste de Tukey, com representação de $C$ do desempenho médio das lagoas em cada fase em relação à eficiência de remoção de Sulfeto $(A)$ e representação de $C$ do desempenho médio das lagoas em cada fase em relação a eficiência de remoção de $\mathrm{CO}_{2}(\mathrm{~B})$

\subsection{Análise da viabilidade técnica das Lagoas de Transbordo}

A partir dos resultados expostos pode-se concluir que a utilização de uma lagoa de transbordo traz vantagens que vão além da simples função de um tanque de equalização e transferência, evidenciando, desse modo, sua viabilidade. Contudo, para determinar a viabilidade técnica financeira da sua utilização na prática, é necessário que sejam avaliados os custos de construção da LT. Sua utilização melhora as características do efluente do UASB e pode facilitar o funcionamento das LP subsequentes. As seguintes vantagens principais podem ser destacadas:

- Alta eficiência na remoção de sólidos sedimentáveis: o reator UASB pode ser operado sem descarga de lodo - isto é, o lodo em excesso no reator UASB será descarregado na lagoa de transbordo onde é separado da fase líquida por sedimentação. Isso vale para todas as profundidades e todos os tempos de permanência pesquisados. 0 efluente decantado segue para a lagoa de polimento e os sólidos para secagem de lodo. Assim, o reator UASB sempre operará com a massa máxima de lodo, o que maximiza a eficiência da digestão anaeróbia;

- Melhoramento do efluente em termos de remoção de DQO, em especial nos maiores TDH;

- Crescimento inicial de algas no efluente da LT, em especial em lagoas de 1 a 2 metros, permitindo que estas atuem como inóculo de algas para LPBS, de modo que a fotossíntese nesta última ocorra a uma taxa elevada, imediata a sua alimentação;

- Eventual oxigênio dissolvido presente na LT é utilizado para oxidação parcial ou completa de sulfeto (fator dependente da altura e TDH adotado para a lagoa), eliminando parcial ou completamente os maus odores, causando sua meIhor aceitação;

- Com a redução dos sólidos em suspensão oriundos do reator UASB há, consequentemente, a redução da carga orgânica sobre as LPBS subsequentes, facilitando a função destas na remoção da concentração residual de material orgânico e dos nutrientes; 
- A menor concentração de material orgânico diminui sua taxa de oxidação e de produção de $\mathrm{CO}_{2}$, acelerando a remoção de acidez e aumento do $\mathrm{pH}$.

- Nas LT há também a dessorção de $\mathrm{CO}_{2}$, que provoca diminuição da acidez do efluente e, consequentemente, facilita o aumento do $\mathrm{pH}$ nas LPBS; e

- O tempo de detenção na LT favorece ainda a sedimentação de considerável parte de ovos de helmintos.

Todas essas vantagens irão proporcionar meIhores condições de tratamento nas lagoas de polimento com possibilidades de atendimento aos padrões de qualidade desejados de modo mais rápido e eficiente e, por consequência, um menor TDH é possível.

Com a diminuição do TDH há uma redução de custos na construção das lagoas de polimento, a serem direcionados para a LT. Ainda que em termos construtivos pareça não haver diferença de custo, em termos técnicos a facilidade operacional que a lagoa de transbordo proporciona pode implicar na economia de gastos a longo prazo.

\section{CONCLUSÃO}

As lagoas de transbordo apresentaram boa eficiência na remoção dos sólidos e matéria orgânica. Para o parâmetro de sólidos suspensos totais e voláteis, o desempenho não demostrou diferença significativa entre os TDH, de modo que o menor TDH investigado (1,5 d) já foi suficiente para remoção dos sólidos expulsos do reator UASB.

A ocorrência de clorofila a foi bastante evidente na primeira fase com TDH de $3 \mathrm{~d}$, de modo a serem um potencial inóculo às LP.

A concentração de OD apresentou uma redução com o aumento da profundidade e com a dimi- nuição do TDH. Consequentemente, a remoção de sulfeto foi maior nos maiores THD e menores alturas, seguindo também esse mesmo padrão.

Houve uma considerável dessorção de $\mathrm{CO} 2$, com eficiências entre 40 e $80 \%$, seguindo da mesma forma um padrão com o aumento do TDH e diminuição da altura, provocando uma redução da acidez do efluente na mesma proporção. Com esse resultado prova-se também que o ambiente será mais favorável à redução da acidez e ao aumento do $\mathrm{pH}$ nas LP subsequentes.

As lagoas de transbordo apresentaram desempenho excelente na remoção de ovos de helmintos, com mais de $90 \%$ de eficiência em todas as lagoas e fases analisadas.

Conclui-se, por fim, que lagoas de transbordo podem ser consideradas uma alternativa promissora no melhoramento de efluentes anaeróbios destinados a LP.

\section{AGRADECIMENTOS}

Os autores agradecem ao Conselho Nacional de Desenvolvimento Científico e Tecnológico (CNPq) pelo incentivo financeiro às pesquisas

\section{CONTRIBUIÇÃO DOS AUTORES}

Todos os autores contribuíram de forma igualitária.

\section{REFERÊNCIAS}

ALBUQ⿱UERQQUE, M. S.; SANTOS, S. L.; VAN HAANDEL, A. Influência do regime hidrodinâmico sobre o desempenho de lagoas de polimento. Revista DAE: Edição especial, São Paulo, n. 229, março 2021.

AMERICAN PUBLIC HEALTH ASSOCIATION - APHA. Standard Methods for the Examination of Water and Wastewater. 22. ed. Washington D C. 2012.

ASSOCIAÇÃO BRASILEIRA DE NORMAS TÉCNICAS. NBR 12209: Elaboração de projetos hidráulicos-sanitários de estações de 
tratamento de esgoto sanitário. 1 ed. Rio de Janeiro: Abnt, 2011. $53 \mathrm{p}$.

AYRES, R. M.; MARA, D. D. Analysis of wastewater for use in agriculture: a laboratory manual of parasitological and bacteriological techniques. Geneva: World Health Organization, 1996.

BATISTA, M. M.; LAMBAIS, G. R.; SANTOS, S. L.; VAN HAANDEL, A. Decaimento bacteriano em lagoas de polimento tratando efluente de reator UASB. Revista DAE: Edição especial, São Paulo, n. 229, março 2021.

BRYANT, C. W. Lagoons, Ponds, and Aerobic Digestion. Journal (Water Pollution Control Federation), v. 58, n. 6, p. 501-504, 1986.

CAVALCANTI, P.; VAN HAANDEL, A.; LETTINGA, G. Sludge accumulation in polishing ponds treating anaerobically digested wastewater. Water Science and Technology, v. 45, n. 1, p. 7581, 2002.

CAVALCANTI, P. F. F. Aplicação de Reatores UASB e Lagoas de Polimento no Tratamento de Esgoto Doméstico. João Pessoa: Gráfica Santa Marta, $1^{\text {a }}$ Ed, p. 172, 2009. https://doi. org/10.2166/wst.2002.0011

CHERNICHARO, C. A.; RIBEIRO, T. B.; PEGORINI, E. S.; et al. Contribuição para o aprimoramento de projeto, construção e operação de reatores UASB aplicados ao tratamento de esgoto sanitário - Parte 1: Tópicos de Interesse. Revista DAE, v. 66, n. 214, p. 5-16, 2018. https://doi.org/10.4322/dae.2018.038

COURAS, C. S. et al. Effects of operational shocks on key microbial populations for biogas production in UASB (Upflow Anaerobic Sludge Blanket) reactors. Energy, 76, p.866-874, jun. 2014. https://doi.org/10.1016/j.energy.2014.06.098

FORESTI, E.; ZAIAT, M.; VALLERO, M. Anaerobic Processes as the Core Technology for Sustainable Domestic Wastewater Treatment: Consolidated Applications, New Trends, Perspectives, and Challenges. Reviews in Environmental Science and Bio/ Technology, v. 5, n. 1, p. 3-19, 2006. https://doi.org/10.1007/ s11157-005-4630-9

GLAZ, P. et al. Greenhouse gas emissions from waste stabilisation ponds in Western Australia and Quebec (Canada). Water Research, v. 101, p. 64-74, 2016. https://doi.org/10.1016/j. watres.2016.05.060

KEHL, O. et al. Analysis of design approaches for stabilization ponds under different boundary conditions - A comparison. $v$. 35, p. 1117-1128, 2009.

KONATÉ, Y.; MAIGA, A.H.; BASSET, D.; et al. Parasite removal by waste stabilization pond in Burkina Faso, accumulation and inactivation in sludge. Ecological Engineering, v. 50, p. 101106, 2013. https://doi.org/10.1016/j.ecoleng.2012.03.021
KAPP H. Schlammfaulung mit hohem Feststoffgehalt. Stuttgarter Berichte zur Siedlungswasserwirtschaft, Band 86, OIdenbourg Verlag, München, 300 p. 1984.

$\mathrm{LI}, \mathrm{M}$. et al. On the hydrodynamics and treatment efficiency of waste stabilisation ponds: From a literature review to a strategic evaluation framework. Journal of Cleaner Production, 2018.

MARA, D. D.; PEARSON, H. W. Waste Stabilization Ponds. Design Manual for Mediterranean Europe. The Hague: Regional Office for Europe Copenhagen, p. 1 - 591987.

MORAIS C. E. P.; SANTOS S.L; VAN HAANDEL, A. Determinação de constantes de transferência de compostos voláteis em lagoas de tratamento de esgoto. Revista DAE: Edição especial, São Paulo, n. 229, março 2021.

OLUKANNI, D. O.; DUCOSTE, J. J. Optimization of waste stabilization pond design for developing nations using computational fluid dynamics. Ecological Engineering, v. 37, n. 11, p. 18781888, 2011. https://doi.org/10.1016/j.ecoleng.2011.06.003

RAMOS, R. A. Avaliação da influência da operação de descarte de lodo no desempenho dos reatores UASB em estações de tratamento de esgotos no Distrito Federal. 2008. 135 p. Dissertação (Mestrado em Tecnologia Ambiental e Recursos Hídricos, Engenharia Civil e Ambiental), Universidade de Brasília, Brasília, 2008.

SANTOS, S. L.; SIMÕES, J. P. O; PAIVA, F. V.; VAN HAANDEL, A. Design optimization of a simple single family anaerobic sewage treatment system. Water Practice and Technology, 2016. https://doi.org/10.2166/wpt.2017.010

SANTOS, I.V.; SANTOS, S. L.; VAN HAANDEL, A. Remoção de fósforo em lagoas de polimento operadas em regime de bateladas sequenciais. Revista DAE: Edição especial, São Paulo, n. 229, março 2021.

VAN HAANDEL, A.; SANTOS, S. L. Transformação de lagoas de estabilização: reengenharia de um sistema obsoleto de tratamento de águas residuárias. Revista DAE: Edição especial, São Paulo, n. 229, março 2021.

VAN HAANDEL, A.; SANTOS, S. L. Variação do pH e remoção de nitrogênio em lagoas de polimento. Revista DAE: Edição especial, São Paulo, n. 229, março 2021.

VAN HAANDEL, A. C. Possíveis causas e medidas para remediar e evitar o ressurgimento da cor púrpura nas lagoas do SIDI em Fortaleza-CE. Parecer técnico. Consultor - Adrianus van Haandel, 22 p. Fevereiro, 2001

VAN HAANDEL, A. C. e CATUNDA, S.Y.C. Respirometria aplicada ao sistema de lodo ativado: teoria e aplicações. 1 ed. Campina Grande: Epgraf, 2013.

VAN HAANDEL, A.C. e LETTINGA, G. Tratamento anaeróbio de esgotos: Um manual para regiões de clima quente. Campina Grande: Epgraf, 1994, 240p. 
VAN HAANDEL, A. C; KATO, M. T.; CAVALCANTI, P. F. F.; et al. Anaerobic Reactor Design Concepts for the Treatment of Domestic Wastewater. Reviews in Environmental Science and Bio/ Technology, v. 5, n. 1, p. 21-38, 2006.

VAN HAANDEL, A. C.; van der LUBBE, J. Anaerobic Sewage Treatment: Optimization of Process and Physical Design of Anaerobic and Complementary Processes. London: IWA Publishing, 2019. 429 p. ISBN: 9781780409610.
VAN HAANDEL, A; SANTOS, Silvânia Lucas dos; CHAVES, Sílvia Raphaele Morais; et al. Influência do projeto do separador de fases no desempenho do reator UASB no tratamento de águas residuais municipais. Revista DAE, v. 63, n. 200, p. 64-75, 2015.

VERBYLA, M. E.; OAKLEY, S. M.; MIHELCIC, J. R. Wastewater Infrastructure for Small Cities in an Urbanizing World: Integrating Protection of Human Health and the Environment with Resource Recovery and Food Security. Environmental Science \& Technology, v. 47, n. 8, p. 3598-3605, 2013. 